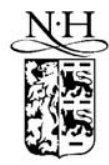

ELSEVIER
Journal of International Economics 59 (2003) 25-45

\title{
The market microstructure of central bank intervention
}

\author{
Kathryn M.E. Dominguez* \\ University of Michigan, Gerald R. Ford School of Public Policy, Ann Arbor, MI 48109, USA
}

Received 2 September 1999; received in revised form 7 September 2001; accepted 31 August 2002

\begin{abstract}
How quickly do central bank intervention operations impact the foreign exchange market? And, do intra-daily market conditions influence the effectiveness of central bank interventions? This paper uses high-frequency intra-daily data to examine the relationship between the efficacy of intervention operations and the "state of the market" at the moment that the operation is made public. The results indicate that some traders typically know that the Fed is intervening at least $1 \mathrm{~h}$ prior to the public release of the information in newswire reports. Also, the evidence suggests that the timing of intervention operations mattersinterventions that occur during heavy trading volume, that are closely timed to scheduled macro announcements, and that are coordinated with another central bank are the most likely to have large effects.

(C) 2002 Elsevier Science B.V. All rights reserved.
\end{abstract}

Keywords: Central bank intervention; Foreign exchange rates; Market micro structure

JEL classification: F31; G14; G15; E58

\section{Introduction}

How does information influence intra-daily exchange rate behavior? Standard models of exchange rate determination distinguish the types of information that should influence exchange rate movements, but there has been little focus on the way this information is assimilated by market participants. For example, in most

*Tel.: + 1-734-764-9498; fax: +1-734-763-9181.

E-mail address: kathrynd@umich.edu (K.M.E. Dominguez). 
models of exchange rate determination an unanticipated (and exogenous) monetary contraction in the home country leads to an appreciation of the home currency relative to foreign currencies. Standard models have little to say about how market participants learn of the monetary contraction, or of how the state of the foreign exchange market might influence the immediate and longer-term reactions of individual foreign exchange traders to the news of such a contraction. One possible explanation for the inadequate empirical performance of standard exchange rate models is that they put so little emphasis on the market microstructure of the foreign exchange market.

This paper focuses on one important source of information to the foreign exchange markets, the intervention operations of the G-3 central banks. Previous studies using daily and weekly foreign exchange rate data suggest that central bank intervention operations can influence both the level and variance of exchange rates, $^{2}$ but little is known about how exactly traders learn about these operations and whether intra-daily market conditions influence their effectiveness. This paper uses high-frequency intra-daily spot market data to examine the relationship between the efficacy of intervention operations and the "state of the market" at the moment that the operation is made public to traders. The results indicate that some traders know that the Fed is intervening at least $1 \mathrm{~h}$ prior to the public release of the information in newswire reports. Also, the evidence suggests that the timing of intervention operations matter-interventions that occur during heavy trading volume and that are closely timed to scheduled macro announcements are the most likely to have large effects. Finally, results indicate that interventions that are coordinated with another central bank have the largest price impact.

The data used in this study include all the days that the Fed intervened in the USD-DEM or USD-JPY markets over the period 1987 through 1995, allowing tests for systematic influences of interventions over a relatively long time series, though the nature of the data do not allow tests for the persistence of interventions' influence beyond the day. ${ }^{3}$ Previous intra-daily studies of intervention have had to focus on much shorter time spans due to the relative unavailability of both intervention data and high-frequency exchange rate data. ${ }^{4}$ This study is also able to control for the influence of other intra-daily news using time-stamped Reuters' newswire reports.

Section 2 of the paper presents stylized facts on the foreign exchange market,

\footnotetext{
${ }^{1}$ See, for example, Meese and Rogoff (1983) and Frankel and Rose (1995), and see Lyons (2001) for a thorough discussion of the role of market microstructure in international finance.

${ }^{2}$ See, for example, Dominguez (1992, 1998) and Dominguez and Frankel (1993a,b).

${ }^{3}$ Two additional Fed intervention operations have occurred since August 1995. On June 17, 1998 the Fed sold $\$ 833$ million against the yen in cooperation with the BOJ and on September 22, 2000 the Fed purchased a total of 1.5 billion euros against the dollar in cooperation with the ECB, the BOJ, the Bank of Canada and the Bank of England.

${ }^{4}$ For example, Goodhart and Hesse (1993), Peiers (1997), Chang and Taylor (1998), Beattie and Fillion (1999), Fischer and Zurlinden (1999), Payne and Vitale (2000), and Neely (2002).
} 
central bank interventions, and Reuters' news reports. Section 3 reviews the role of interventions in the market microstructure of foreign exchange markets. Section 4 examines empirically the influence of market microstructure on the efficacy of central bank intervention, and Section 5 is the conclusion.

\section{Stylized facts}

\subsection{The foreign exchange market}

The foreign exchange market is de-centralized and open 24 hours a day. Even though foreign exchange trading occurs at all hours, there appear to be three distinct geographical "markets" defined by daylight hours in Tokyo, London and New York. There is a small overlap between Asian and European trading, substantial overlap between European and American trading, and no overlap between American and Asian trading. It is during the overlap in European and American trading that volume is typically highest in the foreign exchange market.

The exchange rate data used in this paper are the Reuter's FXFX series tick-by-tick indicative quotes on Fed intervention days as well as a control sample of 25 days with no interventions. ${ }^{5}$ The FXFX data identify a potential source of market heterogeneity by including in the data set the names and locations of quoting banks. A limitation of the FXFX data, however, is that because they are quotes and not transactions they do not provide volume information, so it is not possible to examine the joint dynamics of volume (or order flow) and price. ${ }^{6}$ Another disadvantage of the data set is that, because it includes only intervention days, it is not possible to measure persistent effects of interventions.

\subsection{Central bank intervention}

In the United States, the New York Fed implements intervention operations, while the decision to intervene is made by the Treasury Department. ${ }^{7}$ As with any other foreign exchange transaction, intervention trades are officially anonymous.

\footnotetext{
${ }^{5}$ The data are collected by Olsen and Associates (Research Institute for Applied Economics, Zurich Switzerland) using O\&A proprietary real-time data collection software and are filtered as recommended by Dacorogna et al. (1993). The control dates were selected to provide a representative sample of non-intervention days over the period when the intervention operations take place. These data are used to test whether the volatility of exchange rates differs in periods when central banks are intervening as compared to periods of non-intervention.

${ }^{6}$ See Goodhart et al. (1996), Evans (1998, 1999) and Lyons (1995, 1996, 2001) for comparisons of the FXFX quote data and transaction data.

${ }^{7}$ Prior to 1992 the Fed conducted its foreign exchange transactions exclusively with commercial bank dealers, but in 1992 the Federal authorized relationships (for intervention purposes) with securities dealers (Federal Reserve Bank of New York, 1992).
} 
However, most central banks have developed relationships with traders that allow them to inform the market of their presence within minutes of the original transaction, or to keep their intervention operations secret. ${ }^{8}$

The G-3 central banks intervened sporadically over the period 1987 through 1995. There are 273 days in the 9-year sample when the Fed intervened in the USD-DEM or the USD-JPY market. Moreover, the Bundesbank and the BOJ frequently intervened on the same days as the Fed, so that the sample of Fed intervention days also includes interventions by all three central banks. ${ }^{9}$ In order to analyze the influence of intervention on the intra-daily data, ideally one would like to know the exact time that each central bank entered the market to buy or sell foreign exchange. Unfortunately, such data (rounded to the nearest minute) are only available for the Fed in the last two years of the sample. ${ }^{10}$ However, on most days when central banks are in the market, Reuters reports the timing of their interventions and the time-stamped history of these reports are also available from Olsen and Associates. ${ }^{11}$ To illustrate, Fig. 1 presents the DEM-USD tick-by-tick FXFX quotes for one of the last days in the sample, May 31, 1995, along with an indication of when the Reuters' time-stamped reports of the three Fed intervention operations appeared. On this particular day the DEM-USD price jumped from 1.38 to over 1.40 just before the first Reuters' report of Fed intervention and there are no signs of price mean reversion within the day.

It is possible that some traders in the market will learn that a central bank is in the market before the story appears in a Reuters' report. (It is indeed likely that the trading desks in the first bank (or banks) with which the central bank purchases or sells foreign exchange will know about the intervention before all the other banks.) Therefore, although we can assume that all traders know about the occurrence of intervention when the Reuters' report is released, it is possible that some (or even the bulk) of the influence of intervention will occur before the Reuters' time-

\footnotetext{
${ }^{8}$ Dominguez and Frankel (1993b) provide a detailed description of this process and the possible reasons that central banks might want to keep their intervention operations secret (the so-called stealth operations). Neely (2000) notes that central banks are moving increasingly toward electronic trading methods, which suggests that they are less interested in keeping operations secret.

${ }^{9}$ In 111 of the 273 days in the full sample the Fed was reported to have intervened unilaterally. On 80 of the remaining days (or 29\%) two central banks (from among the Fed, Bundesbank and BOJ) were reported to have intervened. On 10 days (or 4\%) all three G-3 central banks were reported to have intervened. And, on 29 days (11\%) more than 3 central banks were reported to have intervened.

${ }^{10}$ The two other central banks that have kept records of the timing of their interventions (and provided the data to researchers) are the Swiss National Bank and the Bank of Canada.

${ }^{11}$ At a daily frequency, 25\% (25 out of 101 days) of the Fed interventions that occurred over the period 1989-1995, were not reported by Reuters. 8 of the days occurred in August and September 1989 and the other 13 days occurred between May and July 1990. The average absolute daily value of non-reported Fed interventions was $\$ 80 \mathrm{~m}$ (median $\$ 77 \mathrm{~m}$ ), whereas the value of reported Fed interventions averaged $\$ 319 \mathrm{~m}$ (median $\$ 188 \mathrm{~m}$ ). It is not possible to check whether Reuters reported interventions that did not occur (false positives) because the Reuters data were only made available on the days on which the Fed (officially) intervened.
} 


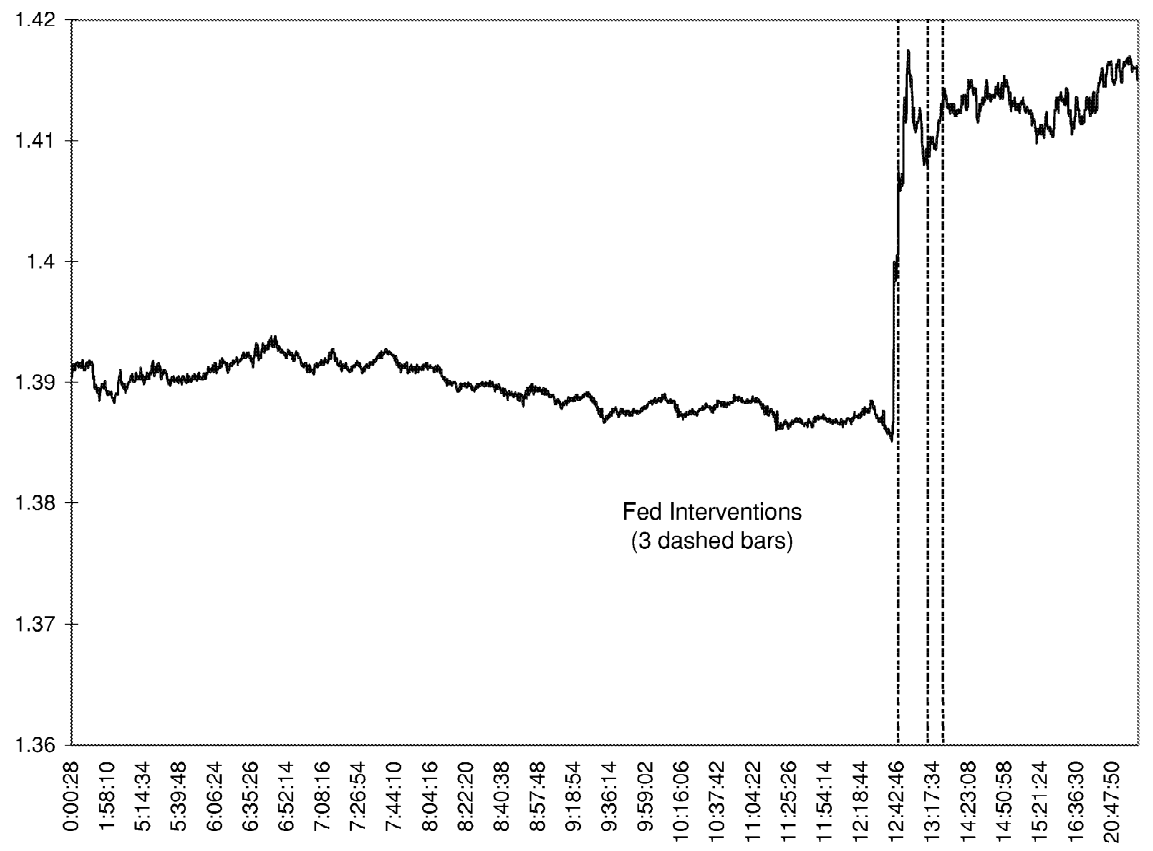

Fig. 1. DEM-USD exchange rate and Fed interventions on May 31, 1995.

stamp. (This is the likely explanation for why the DEM-USD rate in Fig. 1 jumped prior to the Reuters' report.)

Typically, central banks intervene during business hours in their own respective markets. For example, the Fed generally intervenes between 8 am and $5 \mathrm{pm}$ Eastern Standard Time. According to the Reuters times-stamp, on average the Fed intervenes at 14:57:10 GMT (or 10 am EST), the Bundesbank intervenes at 11:31:16 GMT (or at 12:30 pm in Frankfurt) and the BOJ intervenes at 3:56:36 GMT (or around the Tokyo lunch hour). Fig. 2 presents the frequency distribution of Reuters reports of intervention times for the Fed. The graph clearly illustrates that there is a wide range of times at which the Fed enters the market.

Quite apart from the decision of when and how to intervene, central banks have varied goals for their intervention operations. The Fed describes four different reasons for its interventions in foreign exchange markets: to influence trend movements in exchange rates, to calm disorderly markets, to rebalance its foreign exchange reserve holdings, and to support fellow central banks in their exchange rate operations. Unfortunately, central banks rarely provide traders (or researchers) information regarding their specific goals for particular intervention operations. This lack of information, in turn, makes it difficult to access the "success" of individual intervention operations. Further, the magnitude and persistence of 


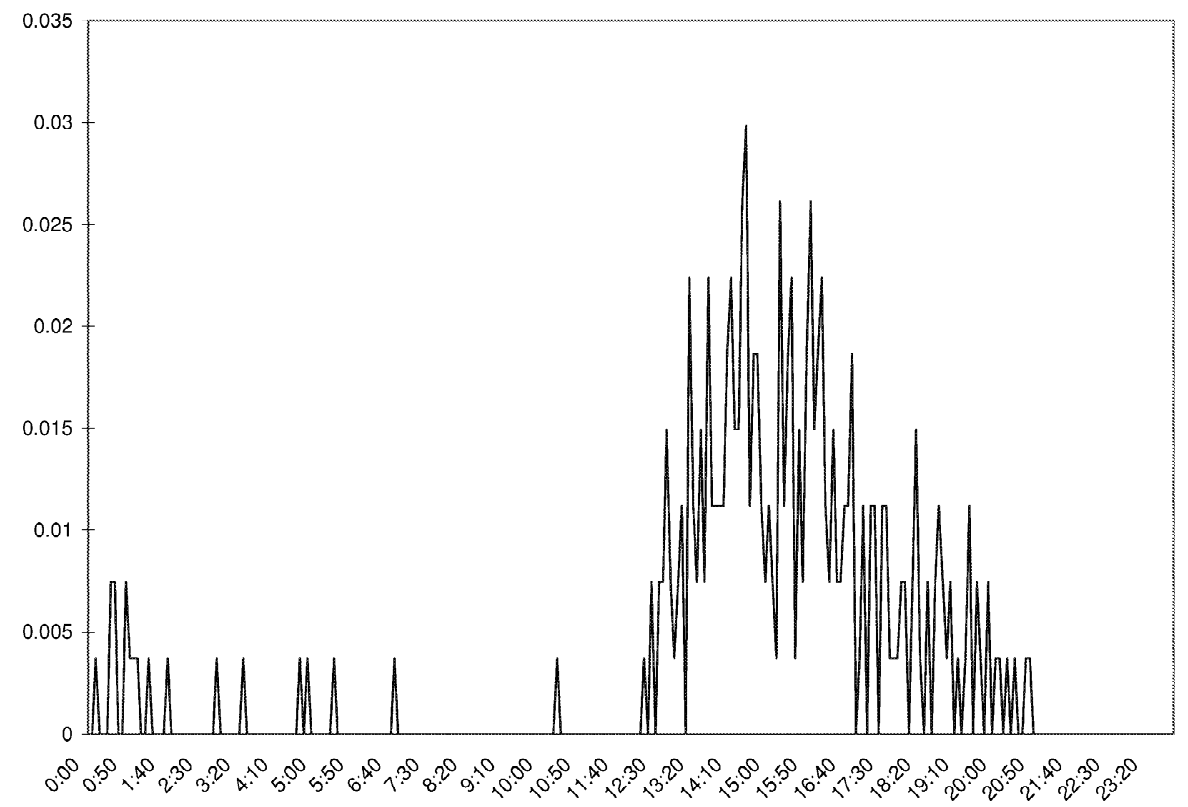

Fig. 2. Frequency distribution of the intradaily timing of Fed interventions, 1987-1995.

intervention's influence are likely to depend importantly on the interaction of the central bank's goals and the market's perception of those goals.

Theory provides at least two channels whereby central bank interventions may influence exchange rates, the portfolio balance and the signaling channel. A recent study by Evans and Lyons (2001) focuses on the portfolio balance channel by assuming that private transactions can serve as a proxy for secret interventions. The interventions studied here are explicitly non-secret, in that the timing information for the operations is taken from contemporaneous Reuters' newswire reports, so that both channels of influence may be operative. ${ }^{12}$

The empirical work that follows measures the impact of intervention operations on foreign exchange rate prices and volatility, and the extent to which this impact,

\footnotetext{
${ }^{12}$ See Mussa (1980) and Dominguez (1992) for further discussion of the intervention-signaling hypothesis. Montgomery and Popper (2001) suggest that central bank intervention may also serve to aggregate and disseminate traders' information and thereby serve an informational sharing role for a heterogeneously informed market. Naranjo and Nimalendran (2000) hypothesize that non-secret interventions create significant adverse selection problems for dealers. They find evidence in daily data that dealers increase exchange rate spreads around interventions and suggest that in doing so they protect themselves against the greater informational asymmetry around interventions.
} 
and subsequent effects of intervention, depend on the "state of the market"13 In particular, the tests will examine the relevance of the: (1) volume of trading, (2) proximity to other macro news, and the (3) presence of other central banks in the market, to the efficacy of intervention. The data also allow us to examine whether different central banks have different impacts on currencies, whether the market anticipates Reuters' reports of intervention operations, and whether exchange rates exhibit intra-daily mean reversion in reaction to intervention news.

\subsection{Reuters news reports}

The Reuters news reports are available from the Reuters AAMM Page News (Money Market Headline News) starting in 1989. Along with reports of central bank intervention, the Reuters data include announcements of various macroeconomic statistics, statements by central bank and government officials and reports of major economic events. In order to control for the impact of other news on exchange rate returns, a subsample of these Reuters news reports are also included in the empirical work. In particular, dummy variables indicate the timing of all major macroeconomic announcements and statements regarding exchange rate policy by officials of the G-3 central banks on the intervention sample days. ${ }^{14}$

\section{The role of interventions in market microstructure models}

The market microstructure literature analyzes ways in which specific trading mechanisms affect the price formation process. ${ }^{15}$ The two branches of microstructure theory, the inventory approach and the informational approach, both provide implications for the effects of intervention operations on exchange rate movements. ${ }^{16}$

The inventory branch of the microstructure literature examines the question of what happens when orders to buy or sell are not always balanced in the selected time period. How does the price change to reflect order flow? In the context of inventory models, a central bank's order (intervention) can have both temporary and persistent effects. Interventions can influence bid-ask spreads, order flow and depending on the degree of risk aversion among market participants, the level of

\footnotetext{
${ }^{13}$ Of the four reasons that the Fed intervenes, only one (when the goal is to rebalance its portfolio) does not involve a desired change in the level or volatility of exchange rates. The tests in this paper are predicated on the assumption that relatively few interventions take place for the sole purpose of portfolio rebalancing.

${ }^{14}$ Table 2 in Dominguez (1999) lists the fifteen dummy variables created from the Reuters News Reports and the day-of-week and average time (GMT) when the announcements are made.

${ }^{15}$ See, for example, Admati (1991), O'Hara (1995) and Lyons (2001).

${ }^{16}$ See Pasquariello (2001) for a thorough theoretical treatment.
} 
the exchange rate through the portfolio balance channel. Unfortunately the nature of the indicative quotes used in this study do not allow examination of either spreads or order flow, ${ }^{17}$ but they will allow tests for whether interventions influence returns (and therefore prices).

The information branch of the microstructure literature focuses on the question of how prices may be affected by the fact that traders in the market may have different information. In these models periods of high variance correspond to periods of high concentration of informed trading (because during heavy volume informed traders can more easily hide their trades). If we assume that intervention operations constitute private information (at least initially), information theory suggests that volume and volatility are likely to rise during and immediately after an intervention operation. Currency prices and returns are also likely to change in reaction to intervention news, depending on how the news influences traders' forecasts of future currency movements. Once intervention news is fully revealed to the market (and all uncertainty is resolved), theory suggests that volatility (and volume) should revert back to initial levels.

\section{Systematic influences of central bank interventions}

A fundamental property of high frequency data in general, and the FXFX indicative quotes used in this study, is that observations occur at varying time intervals resulting in irregular spacing of data. Standard econometric techniques require regularly spaced data. As a consequence, a 5-min price (and returns) series was formed from the irregularly spaced data by averaging the two immediately adjacent bid and ask observations to the round 5-min mark with weights proportional to the distance from the end of the interval. ${ }^{18}$

Table 1 presents descriptive statistics (means, variance, skewness, kurtosis) of the 5-min FXFX returns data used in this study as well as corresponding statistics on the full sample of FXFX returns data from 1987 to 1993 (this data set contains $8,238,532$ observations for the USD-DEM rate and 4,230,041 observations for the USD-JPY rate). ${ }^{19}$ Mean returns and sample variances on the Fed intervention days are significantly larger than they are over the full sample period or the control sample. $^{20}$ Interestingly, mean returns are positive on the Fed intervention days, while they are negative over the full sample and of mixed signs in the control

\footnotetext{
${ }^{17}$ The FXFX indicative bid-ask spreads have not been found to be good proxies for actual transaction spreads. Likewise, the technical limitations of the FXFX transmission process are likely to bias measures of volume particularly during times of heavy trading.

${ }^{18}$ Results are essentially unchanged when data are sampled at 5-, 10- or 15-min intervals. Central banks often intervene on multiple occasions during 1 day, the 5-min intervals allow a maximal disaggregation of these individual operations.

${ }^{19}$ The full sample statistics in the upper panel of Table 1 are reproduced from Table 4 in Guillaume et al. (1997).

${ }^{20}$ This is also true at a daily frequency, see Chaboud and LeBaron (2001) and LeBaron (1999).
} 
Table 1

Descriptive statistics of the FXFX return distribution

\begin{tabular}{|c|c|c|c|c|c|}
\hline Rate & Time int. & Mean & Variance & Skewness & Kurtosis \\
\hline \multicolumn{6}{|c|}{ Full sample of FXFX data 1987-1993 (based on 8,238,532 obs for DEM and 4,230,041 obs for JPY } \\
\hline \multirow[t]{4}{*}{ USD/DEM } & $10 \mathrm{~m}$ & $-2.73 \cdot 10^{-7}$ & $2.62 \cdot 10^{-7}$ & 0.17 & 35.10 \\
\hline & $1 \mathrm{~h}$ & $-1.63 \cdot 10^{-6}$ & $1.45 \cdot 10^{-6}$ & 0.26 & 23.55 \\
\hline & $6 \mathrm{~h}$ & $-9.84 \cdot 10^{-6}$ & $9.20 \cdot 10^{-6}$ & 0.24 & 9.44 \\
\hline & $24 \mathrm{~h}$ & $-4.00 \cdot 10^{-5}$ & $3.81 \cdot 10^{-5}$ & 0.08 & 3.33 \\
\hline \multirow[t]{4}{*}{ USD/JPY } & $10 \mathrm{~m}$ & $-9.42 \cdot 10^{-7}$ & $2.27 \cdot 10^{-7}$ & -0.18 & 26.40 \\
\hline & $1 \mathrm{~h}$ & $-5.67 \cdot 10^{-6}$ & $1.27 \cdot 10^{-6}$ & -0.09 & 25.16 \\
\hline & $6 \mathrm{~h}$ & $-3.40 \cdot 10^{-5}$ & $7.63 \cdot 10^{-6}$ & -0.05 & 11.65 \\
\hline & $24 \mathrm{~h}$ & $-1.37 \cdot 10^{-4}$ & $3.07 \cdot 10^{-5}$ & -0.15 & 4.81 \\
\hline Rate & Time int. & Mean & Variance & Skewness* & Kurtosis* \\
\hline \multicolumn{6}{|c|}{ Fed intervention days $1987-1995$ (based on $1,169,684$ obs for DEM and 438,039 obs for JPY) } \\
\hline \multirow[t]{4}{*}{ USD/DEM } & $5 \mathrm{~m}$ & $4.94 \cdot 10^{-6}$ & $6.85 \cdot 10^{-9}$ & 0.33 & 2.31 \\
\hline & $10 \mathrm{~m}$ & $9.89 \cdot 10^{-6}$ & $1.20 \cdot 10^{-8}$ & -0.17 & 3.23 \\
\hline & $1 \mathrm{~h}$ & $5.42 \cdot 10^{-5}$ & $5.13 \cdot 10^{-8}$ & 1.22 & 3.98 \\
\hline & $24 \mathrm{~h}$ & $1.05 \cdot 10^{-3}$ & $5.95 \cdot 10^{-5}$ & -0.32 & 1.93 \\
\hline \multirow[t]{4}{*}{ USD/JPY } & $5 \mathrm{~m}$ & $9.90 \cdot 10^{-6}$ & $5.02 \cdot 10^{-9}$ & 0.58 & 0.66 \\
\hline & $10 \mathrm{~m}$ & $1.98 \cdot 10^{-5}$ & $9.23 \cdot 10^{-9}$ & 0.41 & -2.63 \\
\hline & $1 \mathrm{~h}$ & $1.14 \cdot 10^{-4}$ & $6.56 \cdot 10^{-8}$ & 0.57 & -0.32 \\
\hline & $24 \mathrm{~h}$ & $2.99 \cdot 10^{-3}$ & $2.95 \cdot 10^{-5}$ & 0.01 & -3.14 \\
\hline Rate & Time int. & Mean & Variance & Skewness* & Kurtosis* \\
\hline \multicolumn{6}{|c|}{ Control sample: 25 days 1987-1993 (based on 108,973 obs for DEM and 49,132 obs for JPY) } \\
\hline \multirow[t]{4}{*}{ USD/DEM } & $5 \mathrm{~m}$ & $-6.84 \cdot 10^{-7}$ & $1.52 \cdot 10^{-9}$ & 0.95 & 5.75 \\
\hline & $10 \mathrm{~m}$ & $-1.37 \cdot 10^{-6}$ & $3.15 \cdot 10^{-9}$ & 1.21 & 1.79 \\
\hline & $1 \mathrm{~h}$ & $1.13 \cdot 10^{-6}$ & $2.61 \cdot 10^{-8}$ & 0.46 & 2.80 \\
\hline & $24 \mathrm{~h}$ & $1.10 \cdot 10^{-3}$ & $2.16 \cdot 10^{-5}$ & 2.29 & 8.53 \\
\hline \multirow[t]{4}{*}{ USD/JPY } & $5 \mathrm{~m}$ & $-3.26 \cdot 10^{-7}$ & $1.07 \cdot 10^{-9}$ & 0.27 & 1.66 \\
\hline & $10 \mathrm{~m}$ & $-6.53 \cdot 10^{-7}$ & $1.96 \cdot 10^{-9}$ & 0.50 & -2.54 \\
\hline & $1 \mathrm{~h}$ & $1.42 \cdot 10^{-5}$ & $2.73 \cdot 10^{-9}$ & -0.53 & 0.59 \\
\hline & $24 \mathrm{~h}$ & $2.25 \cdot 10^{-4}$ & $1.37 \cdot 10^{-5}$ & 0.61 & 0.42 \\
\hline
\end{tabular}

The top panel of data are reproduced from Table 4 in Guillaume et al. (1997).

** The skewness and kurtosis formulas are from Kendall and Stuart (1958).

sample depending on the particular sampling frequency used to create the data series. In the full sample, the degree of kurtosis of the returns rises with increasing sample frequency, while for both the Fed intervention days and the control sample the degree of kurtosis is relatively stable over sampling frequencies and is less pronounced.

\subsection{The influence of intervention on returns}

The empirical work uses an "event study" approach to test for the influence of intervention (and other announcements) on exchange rates. If $\mathrm{R}$ denotes the 5-min 
return series and $\mathrm{D}^{\mathrm{k}}$ denotes the (time-stamped to the nearest 5-min) signed intervention $^{21}$ and other announcement dummy variables, then a general "event study" regression specification is:

$$
R_{t_{i}}-\overline{R_{t_{i}}}=\alpha_{0}+\sum_{k} \sum_{n} \alpha_{1, n}^{k} D_{t_{i+n}}^{k}+\varepsilon_{t_{i}}
$$

where $\bar{R}$ is set to zero and the intra-daily returns data include only the days on which the Fed intervened in the market over the sample. Using this general regression specification it is possible to test for the impact and intra-day effects of signed intervention (and other macro news) by examining whether the $D^{k}$ s are statistically significant. ${ }^{22}$ Further, the specification can be adjusted to test whether market participants react to the intervention operations of different central banks similarly by including these operations separately in the regression. The possibility that certain market participants know about the interventions before others can be tested by looking for evidence of price effects prior to the time-stamped Reuters release of $D^{k}$ news. The influence of the "state of the market" can be measured by examining information releases during specific times-of-day. It is also possible to measure whether the effects of interventions that are closely timed with other macroeconomic news announcements differ from those that occur in low news times. Finally, in order to investigate the intra-day persistence of intervention's influence, a test for mean reversion can be constructed by checking whether the $\mathrm{n}$ time lags on the $D^{k}$ s sum to zero.

Results of the various event-study regressions using USD-DEM and USD-JPY data, respectively, are presented in Tables 2 and $3 .^{23}$ In the case of USD-DEM returns, signed interventions by all three G-3 central banks are statistically

\footnotetext{
${ }^{21}$ Interventions by all three central banks take the value 1 if they involve a purchase of dollars, the value -1 if they involve a sale of dollars and 0 otherwise. Interventions are included as $(1,0,-1)$ dummy variables both because the dollar magnitudes are generally only available at a daily (not intra-daily) frequency, and because there is some evidence that the size of interventions depend on market reaction to initial trades suggesting that including magnitudes might engender simultaneity bias.

${ }^{22}$ If the Fed bases its decision to intervene on intra-daily exchange rate movements or volatility then estimation of Eq. (1) will be subject to simultaneity bias. Neely's (2000) survey of central banks suggests that they are more likely to base intervention decisions on longer term objectives (though he suggests that central banks may determine the size of interventions based on market reaction to initial trades).

${ }^{23}$ Various regression specifications were attempted, including imposing a polynomial distributed lag (pdl) structure on the leads and lags of the intervention variables. Tests of the pdl restrictions suggested that the data do not conform to this specification. Experimentation with various lead and lag combinations indicated that $\mathrm{a}[-1 \mathrm{~h},+2 \mathrm{~h}]$ window for the intervention variables and $\mathrm{a}[0,1 \mathrm{~h}]$ window for the macroeconomic announcements was appropriate. In specifications that only included one-time influences (impact effects) of each announcement and intervention variable the right-hand-side variables were generally not found to be significant explainers of returns behavior. Subsample robustness checks for the event-study regressions are available from the author upon request and suggest that the influence of Fed interventions was strongest in the latter part of the sample.
} 
Table 2

Influence of interventions on USD-DEM returns

$$
R_{t_{i}}=\alpha_{0}+\sum_{k} \sum_{n} \alpha_{1, n}^{k} D_{t_{i+n}}^{k}+\varepsilon_{t_{i}}
$$

where $R$ is the 5-min USD-DEM return; the $D^{k}$ s include signed intervention, official central bank announcements and macro announcements; $n=-1$ to $+2 \mathrm{~h}$ for the G-3 intervention variables and official announcements and $n=0$ to $+1 \mathrm{~h}$ for the macro announcements; $t_{i}$ is the sequence of the regular-spaced (every $5 \mathrm{~min}$ ) intra-daily data for all the days on which the Fed intervened against the mark from 1989 to 1995 (69 days and a total of 151 reports of Fed operations). The reported coefficients are multiplied by 1000

\begin{tabular}{|c|c|c|c|c|}
\hline & $\begin{array}{l}\text { Do All G-3 } \\
\text { interventions } \\
\text { matter? }\end{array}$ & $\begin{array}{l}\text { Does trade } \\
\text { volume } \\
\text { matter? }^{\mathrm{a}}\end{array}$ & $\begin{array}{l}\text { Does } \\
\text { proximity to } \\
\text { macro news } \\
\text { matter? }^{\text {b }}\end{array}$ & $\begin{array}{l}\text { Does } \\
\text { coordination } \\
\text { matter? }^{\mathrm{c}}\end{array}$ \\
\hline Independent variable & $\begin{array}{l}\text { Max signf. } \\
\text { coefficient }^{\mathrm{d}}\end{array}$ & $\begin{array}{l}\text { Max signf. } \\
\text { coefficient }\end{array}$ & $\begin{array}{l}\text { Max signf. } \\
\text { coefficient }\end{array}$ & $\begin{array}{l}\text { Max signf. } \\
\text { coefficient }\end{array}$ \\
\hline Fed intervention & $0.685 * *$ & & & \\
\hline Buba intervention & $2.404 * *$ & $2.331 * *$ & $2.413 * *$ & na \\
\hline BOJ intervention & $0.627 *$ & $0.509 \dagger$ & $0.554 \dagger$ & na \\
\hline Official announcements & Yes & yes & Yes & yes \\
\hline Macro controls & Yes & yes & Yes & yes \\
\hline $\begin{array}{l}\text { Fed interventions during } \\
\text { high trade volume }\end{array}$ & & $0.881 *$ & & \\
\hline $\begin{array}{l}\text { Fed interventions during } \\
\text { low trade volume }\end{array}$ & & 0.322 & & \\
\hline $\begin{array}{l}\text { Fed interventions close to } \\
\text { macro news }\end{array}$ & & & $0.734 *$ & \\
\hline $\begin{array}{l}\text { Isolated Fed. } \\
\text { interventions }\end{array}$ & & & $0.521 \dagger$ & \\
\hline $\begin{array}{l}\text { Coordinated G-3 } \\
\text { interventions }\end{array}$ & & & & $1.091 * *$ \\
\hline $\begin{array}{l}\text { Unilateral Fed. } \\
\text { interventions }\end{array}$ & & & & $0.553 \dagger$ \\
\hline $\mathrm{R} 2$ & 0.017 & 0.16 & 0.16 & 0.14 \\
\hline D.W. & 1.88 & 1.88 & 1.88 & 1.87 \\
\hline
\end{tabular}

Number of observations $=19,833$. ${ }^{\text {a }}$ High trade volume is defined as the overlap in US and European trading hours. ${ }^{\mathrm{b}}$ Interventions that occur within $2 \mathrm{~h}$ of a macro news announcement are defined as "close". "Coordinated interventions are defined as Fed interventions that occur on the same day as at least one other of the G-3 central banks. ${ }^{\mathrm{d}}$ The maximum significant coefficient is the largest of the 36 lead and lag coefficients on each of the intervention variables. $* *, *, \dagger$ denote statistical significance at the 1,5 and $10 \%$ levels, respectively, using robust standard errors.

significant, have the intended direction of influence on returns, ${ }^{24}$ and in the cases of the Fed and the Bundesbank there is evidence of 1-h Reuters' announcement lags, suggesting that traders were aware of the interventions before the Reuters'

\footnotetext{
${ }^{24} \mathrm{~A}$ positive coefficient on the intervention variables indicates that a purchase (sale) of dollars results in a rise (fall) in the value of the dollar.
} 
Table 3

Influence of interventions on USD-JPY returns

$$
R_{t_{i}}=\alpha_{0}+\sum_{k} \sum_{n} \alpha_{1, n}^{k} D_{t_{i+n}}^{k}+\varepsilon_{t_{i}}
$$

where $R$ is the 5-min USD-JPY return; $D^{k}$ s include signed intervention, official central bank announcements and macro announcements; $n=-1$ to $+2 \mathrm{~h}$ for the G-3 intervention variables and official announcements and $n=0$ to $+1 \mathrm{~h}$ for the macro announcements; $t_{i}$ is the sequence of the regular-spaced (every $5 \mathrm{~min}$ ) intra-daily data for all the days on which the Fed intervened against the yen from 1989 to 1995 (66 days and a total of 192 reports of Fed operations). The reported coefficients are multiplied by 1000

\begin{tabular}{|c|c|c|c|c|}
\hline & $\begin{array}{l}\text { Do All G-3 } \\
\text { interventions } \\
\text { matter? }\end{array}$ & $\begin{array}{l}\text { Does trade } \\
\text { volume } \\
\text { matter? }^{\mathrm{a}}\end{array}$ & $\begin{array}{l}\text { Does proximity } \\
\text { to macro } \\
\text { news matter? }\end{array}$ & $\begin{array}{l}\text { Does } \\
\text { coordination } \\
\text { matter? }\end{array}$ \\
\hline Independent variable & $\begin{array}{l}\text { Max signf. } \\
\text { coefficient }^{\mathrm{d}}\end{array}$ & $\begin{array}{l}\text { Max signf. } \\
\text { coefficient }\end{array}$ & $\begin{array}{l}\text { Max signf. } \\
\text { coefficient }\end{array}$ & $\begin{array}{l}\text { Max signf. } \\
\text { coefficient }\end{array}$ \\
\hline Fed intervention & $0.921 * *$ & & & \\
\hline Buba intervention & $1.877 * *$ & $1.826 * *$ & $1.901 * *$ & na \\
\hline BOJ intervention & $0.753 \dagger$ & $0.762 \dagger$ & $0.764 \dagger$ & na \\
\hline Official announcements ${ }^{5}$ & yes & yes & yes & yes \\
\hline Macro controls & yes & yes & yes & yes \\
\hline $\begin{array}{l}\text { Fed interventions during } \\
\text { high trade volume }\end{array}$ & & $1.023 * *$ & & \\
\hline $\begin{array}{l}\text { Fed interventions during } \\
\text { low trade volume }\end{array}$ & & $0.759 *$ & & \\
\hline $\begin{array}{l}\text { Fed interventions close } \\
\text { to macro news }\end{array}$ & & & $1.117 * *$ & \\
\hline $\begin{array}{l}\text { Isolated Fed. } \\
\text { interventions }\end{array}$ & & & 0.617 & \\
\hline $\begin{array}{l}\text { Coordinated G-3 } \\
\text { interventions }\end{array}$ & & & & $0.887 * *$ \\
\hline $\begin{array}{l}\text { Unilateral Fed. } \\
\text { interventions }\end{array}$ & & & & 1.535 \\
\hline $\mathrm{R} 2$ & 0.011 & 0.010 & 0.010 & 0.010 \\
\hline D.W. & 1.902 & 1.901 & 1.902 & 1.898 \\
\hline
\end{tabular}

Number of observations $=18,969 .{ }^{a}$ High trade volume is defined as the overlap in US and European trading hours. ${ }^{\mathrm{b}}$ Interventions that occur within $2 \mathrm{~h}$ of a macro news announcement are defined as "close". "Coordinated interventions are defined as Fed interventions that occur on the same day as at least one other of the G-3 central banks. ${ }^{\mathrm{d}}$ The maximum significant coefficient is the largest of the 36 lead and lag coefficients on each of the intervention variables. ${ }^{5}$ Excluding BOJ official announcements. $* *, *, \dagger$ denote statistical significance at the 1,5 and $10 \%$ levels, respectively, using robust standard errors.

reports were released. For all three central banks lagged values of the intervention coefficients continued to be significant for at least $1 \mathrm{~h}$ after the release of the Reuters' report. Four of the twelve macro announcements were found to be significant; and lag effects were found up to $30 \mathrm{~min}$ after the Reuters' time- 
stamp. $^{25}$ The impact of the U.S. GNP announcement on USD-DEM returns was the largest by a wide margin, with U.S. consumer credit and Bundesbank intervention ranked second and third. If we measure the cumulative effect of an average-sized dollar purchase by the Fed (starting $1 \mathrm{~h}$ before the Reuters' report and cumulating the lead and lag coefficients on the signed Fed intervention variable) we find that the maximal effect (of about 7 basis points) comes $30 \mathrm{~min}$ after the Reuters report, and reverts toward zero after $2 \mathrm{~h}^{26}$ This suggests that a billion dollar intervention by the Fed would lead to a 29 basis point maximal price impact. $^{27}$

Fed and Bundesbank interventions are also found to significantly influence USD-JPY returns, although Reuters' announcement lags are only found for the Fed. Interestingly, BOJ intervention was not found to significantly influence USD-JPY returns when the dummy variable denoting official BOJ exchange rate comments is also included in the regression specification. If the BOJ comments are omitted (as reported in the table), BOJ interventions are found to significantly influence the USD-JPY returns with a 30 min Reuters' announcement lag. For all three central banks lagged values of the intervention coefficients continued to be significant in the 2-h period after the release of the Reuters' report. Once again, four of the twelve macro announcement variables were found to be significant, and U.S. GNP had the largest impact on USD-JPY returns by a wide margin. There is little evidence of mean reversion in the coefficient values for Fed intervention in the USD-JPY returns regression, the maximal effect of an average-sized Fed intervention (about 10 basis points) comes 55 min after the Reuters' report, and declines to about 7 basis points after $2 \mathrm{~h}$.

Tables 2 and 3 also report the results of three alternative specifications of the event study regression. The first of these alternative specifications provides a test of whether signed interventions that occur during high volume periods (as proxied by the overlap in the European and NY market $)^{28}$ have different effects from those

\footnotetext{
${ }^{25}$ Coefficient values for the macro variables are not reported in the tables because they serve only as controls in the regression. If there is an expected component to some of the macro announcements, leading to mis-measurement of the news component, this could potentially lead to a bias in all the coefficient values. As a robustness check, the regressions were also run without the macro controls (allowing the error term to capture all the effects of the macro news). The results of this specification of Eq. (1) are qualitatively similar to those reported in the paper and are available from the author upon request.

${ }^{26}$ The estimates suggest that there is mean reversion in exchange rate returns after an intervention event, though this does not preclude the possibility that intervention has lasting effects on the level of exchange rates. For example, in continuous time, if intervention causes the level of the exchange rate to quickly (although not instantaneously) converge to a new equilibrium, the first derivative (returns) will undergo mean reversion. I thank Jay Levin for pointing this out to me.

${ }^{27}$ This is based on the assumption that the average daily Fed intervention operation over this period was $\$ 319 \mathrm{~m}$ and the average intra-daily operation was $\$ 240$ million.

${ }^{28}$ It is also possible to interpret this specification as a test of whether Fed interventions that occur in the NY morning differ from those that occur at other times.
} 
that occur in low volume times. Market microstructure models suggest that it is during high volume periods that information flow tends to be highest. The reported coefficient estimates in the second column of Tables 2 and 3 support this, in that they indicate that the influence of signed Fed interventions on returns is higher during high volume trading hours (defined as 8:30-12 EST or 13:30-17:00 GMT with adjustments for daylight savings time) relative to low volume periods in both currency markets $^{29}$, though the difference in the point estimates on the maximal coefficient values is smaller in the USD-JPY market. ${ }^{30}$ Given that the majority of Fed interventions in the sample period in both markets occurred during high volume trading hours, the Fed seems to have already (perhaps inadvertently) exploited this phenomenon.

Previous studies using high frequency data have found evidence that volume and volatility tend to rise in foreign exchange markets in reaction to macro announcements. Along with controlling for the possible influence of these announcements in the event studies, it might also be the case that there exists an interaction effect between these announcements (and the high volume that ensues) and the influence of intervention operations. For example, it may be that traders are more sensitive to news (including intervention news) at times when other major announcements are released. In order to test this hypothesis, Fed interventions that are timed within a 2-h window of a macro announcement are distinguished from the other interventions in the event study regressions. In the case of Fed interventions in the USD-DEM market, $28 \%$ fell into this category, whereas for Fed interventions in the USD-JPY market, 63\% of interventions were timed close to macro announcements. The results reported in column 3 of Tables 2 and 3 suggest that there does indeed seem to be evidence that signed interventions that closely follow macro announcements have a larger impact on returns than do other interventions. Interestingly, this effect is found to be largest for the Fed interventions in the USD-JPY market where a larger percentage of interventions were closely timed to macro announcements. ${ }^{31}$

In the sample period under study, $81 \%$ of Fed interventions in the USD-DEM market and $88 \%$ of the Fed interventions in the USD-JPY market occur on days when either the Bundesbank or the BOJ (or both) are also intervening. The final alternative specification, tests whether Fed interventions that are coordinated with

\footnotetext{
${ }^{29}$ The USD-DEM coefficient estimates suggest that when volume is high, the price impact of intervention is $28 \%$ higher. Linear restrictions imposing equality of the full set of leads and lags on Fed intervention interacted with the high trading volume dummy variable and the coefficient values for the remaining Fed intervention operations are rejected at the 5\% level for both currencies.

${ }^{30}$ One potential explanation for why the results might differ across the two currency markets is that the US and Europe market overlap may not be the appropriate proxy for high trading volume for the Fed interventions in the USD-JPY market. In order to check whether this might be the case, similar regressions distinguishing interventions that occurred during alternative times were examined. The results did not suggest that any alternative timing would provide a better proxy for high trading volume in the USD-JPY market.

${ }^{31}$ Evans and Lyons (2001) also find that secret interventions are the most effective when the flow of macro news is strong.
} 
one or both of the other G-3 central banks are more influential than unilateral interventions. The results, reported in the final column of Tables 2 and 3, suggest that coordinated G-3 interventions are indeed more effective than unilateral ones for all three central banks. ${ }^{32}$ Similar results have also been found at a daily and weekly frequency, suggesting that the signaling (or information) value of an intervention operation is significantly strengthened by the presence of other central banks in the market (intervening in the same direction).

\subsection{The influence of intervention on volatility}

Along with influencing prices and returns, microstructure theory predicts that interventions may affect volume and volatility through both the inventory and information channels. Further, theory predicts that once intervention information is fully public and all uncertainty is resolved, volatility should revert to its original level. One way to examine the influence of intervention on volatility involves arranging squared returns around interventions according to the intervention event rather than clock time. In this approach, the first observation before an intervention report is the return recorded $5 \mathrm{~min}$ before the intervention report. A 2-h (before and after) window is selected to surround each Fed intervention operation in the two currency markets, USD-DEM and USD-JPY. Subsequent intervention reports that are clustered within the 2 -h window are excluded from the sample. ${ }^{33}$ The squared 5-min returns from this "intervention sample" are then compared against a control sample of matched (by time-of-day and day-of-week) 5-min volatility observations when no intervention was reported. (This sample comes from the control group of 25 days for each currency when no intervention occurred.) So, for example, if the Fed intervened in the USD-JPY market on a Monday at 3:55 GMT, then the 5-min returns $2 \mathrm{~h}$ before and after this event are included in the Fed intervention sample. The matched control sample likewise includes an average of returns on all Mondays in the 2-h window around 3:55 GMT.

The differences between exchange rate volatility surrounding the 2-h Fed intervention and non-intervention periods can be seen in Figs. 3 and 4 for the USD-DEM and USD-JPY markets, respectively. There are a total of 47 (5-min) volatility observations for each intervention: 23 before the report, one for the time that the report appears on the Reuters screen, and 23 volatility observations after the report. The figures indicate that volatility surrounding intervention periods is substantially higher than during non-intervention periods in the full 4 -h window and especially in the $[-30,+30]$ min interval. ${ }^{34}$ The peak difference in volatility

\footnotetext{
${ }^{32}$ It is possible that the larger coordination effect is coming from the fact that the aggregate size of intervention tends to be higher when intervention is coordinated. Because intradaily intervention magnitudes are unavailable, it is not possible to distinguish whether coordination per se is at work here.

${ }^{33}$ This criteria disqualified 151 out of 268 Fed interventions.

${ }^{34}$ There are four 5-min returns in the USD-JPY control sample that are at least three standard deviations away from the mean return, these three observations (out of a total of 6888 observations) were dropped from the control sample.
} 


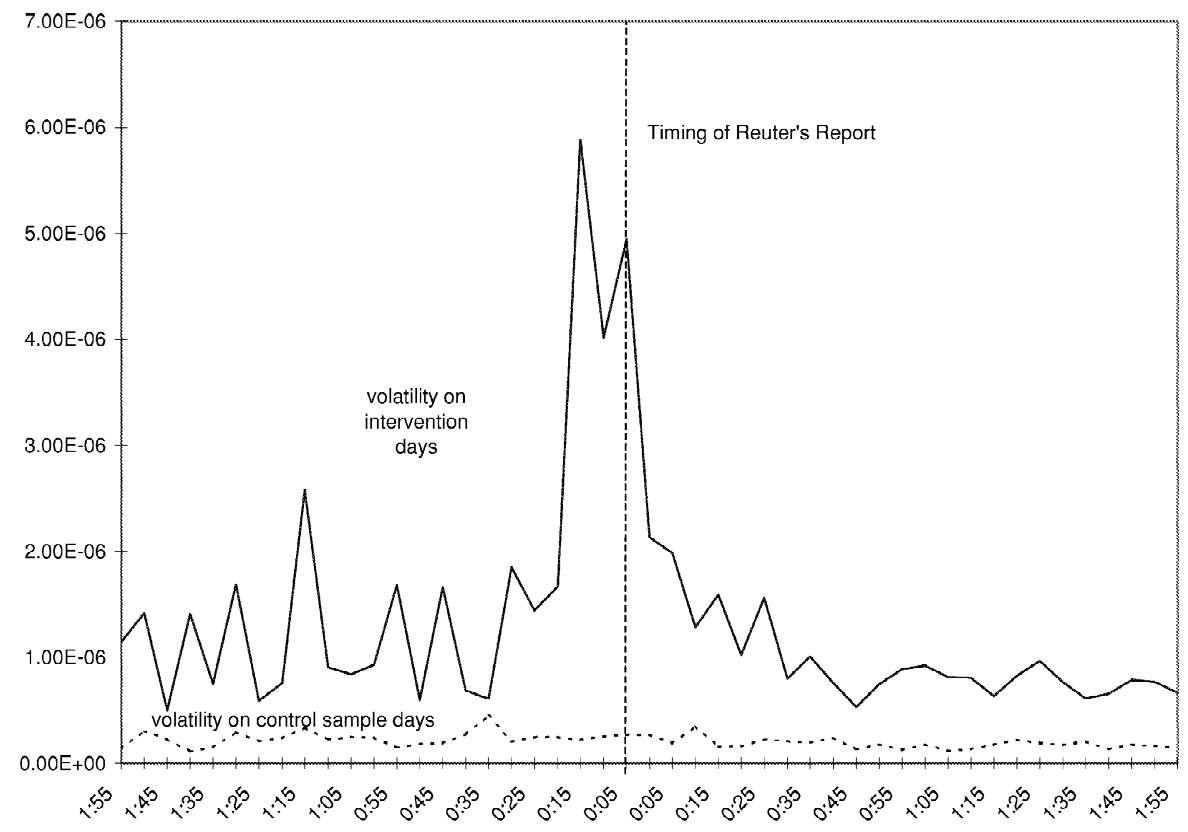

Fig. 3. Variance comparisons of 5-min USD-DEM returns on Fed intervention and control sample (non-intervention) days.

occurs between 5 and $20 \mathrm{~min}$ before the release of the Reuters' reports of intervention (0:00 on the graphs), confirming the evidence found from the event study regressions that some traders are aware of intervention operations before they are reported by Reuters. ${ }^{35}$ The figures also show that volatility on intervention days, while always higher than in the control sample, tends to revert back to its initial level approximately $1 \mathrm{~h}$ after the initial signs of volatility increase. ${ }^{36}$

In order to test the equality of return variances through time in the period surrounding the intervention event versus the matched non-intervention sample a

\footnotetext{
${ }^{35}$ It is also interesting to note in Fig. 4 that there is a second spike in USD-JPY volatility $50 \mathrm{~min}$ after the Reuter's news release, suggesting that trader reactions to the intervention news are neither immediate nor monotonically decreasing. It may also be that other news events are influencing the volatility measure in the second 2 -h period, although there is no evidence of specific outliers in the sample data.

${ }^{36}$ One of the objectives for intervention policy often cited by the Fed (as well as other central banks) is to "calm disorderly markets" and therefore presumably to lower market volatility. Figs. 3 and 4, however, suggest that volatility is higher during intervention days than it is in the control sample of non-intervention days. The figures also show that volatility rises just prior to the Reuters' announcement of a Fed intervention and falls back to its original level about $1 \mathrm{~h}$ later. This suggests that the Fed tends to intervene on days with higher than usual volatility, that operations temporarily increase volatility, but this increase is offset within the hour. The figures provide no evidence that interventions lower volatility at least within the day.
} 


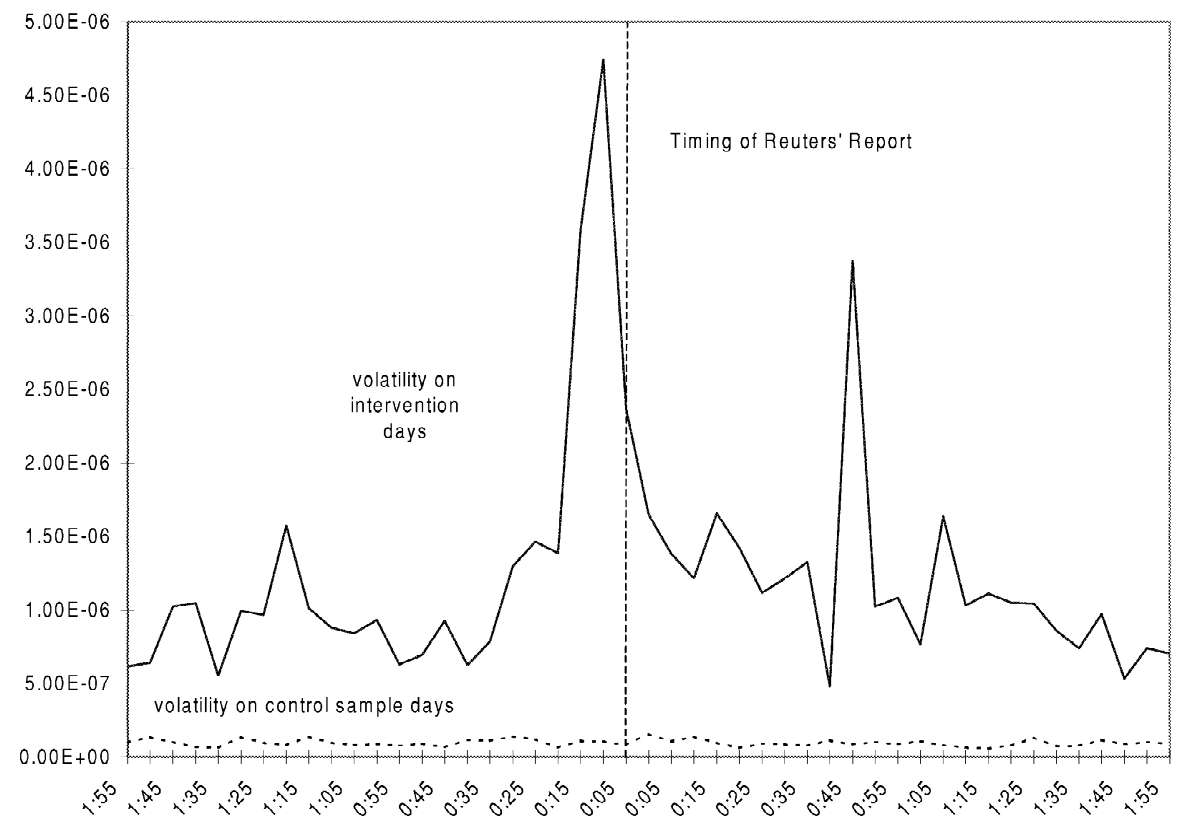

Fig. 4. Variance comparisons of 5-min USD-DEM returns on Fed intervention and control sample (non-intervention) days.

Brown-Forsythe (1974) modified Levene test is used. ${ }^{37}$ The null hypothesis is that the variances at 5-min intervals surrounding the two samples are homoskedastic. Results of these tests are presented in Table 4. The return variance of both the USD-DEM and USD-JPY rates are found to vary significantly around Fed interventions, while in the two control samples, we cannot reject the hypothesis of equal variances

In addition to analyzing whether average volatility in the period surrounding interventions is significantly higher than volatility during matched non-intervention periods, the FXFX data permit a test of whether the variance of quotes from specific banks is responsible for any significant differences. In other words, the test consists of examining quotes from the major banks that deal in the USD-DEM and USD-JPY markets to see if they are more variable around intervention events than is typical at the same times of day on non-intervention days. If certain banks systematically receive information regarding intervention before other banks, then these banks are likely to drive up volatility around intervention events. Table 4

\footnotetext{
${ }^{37}$ The Brown and Forsythe (1974) test is robust to departures of the underlying data from normality. Chang and Taylor (1998) also use this test to examine the intra-day effects of BOJ intervention on USD-JPY volatility.
} 
Table 4

Tests of the equality of return variances $2 \mathrm{~h}$ before and after fed interventions and in matched control samples

\begin{tabular}{lll}
\hline & $\begin{array}{l}\text { Equality of return } \\
\text { variance in Fed. } \\
\text { intervention sample }\end{array}$ & $\begin{array}{l}\text { Equality of return } \\
\text { variance in } \\
\text { control sample }\end{array}$ \\
\hline Full sample quotes & $F$-stats & $F$-stats \\
USD-DEM & $3.4509^{* *}$ & 0.9034 \\
USD-JPY & $1.7147^{* *}$ & 0.8851 \\
Individual bank quotes & & \\
USD-DEM & & \\
Chemical Bank & 0.7657 & 0.9034 \\
Morgan Guaranty & 0.7000 & 0.9034 \\
Citibank & 1.3546 & 0.9034 \\
USD-JPY & & \\
Chemical Bank & $1.4175^{*}$ & 0.8851 \\
Morgan Guaranty & 0.9438 & 0.8851 \\
Citibank & 1.108 & 0.8851 \\
\hline
\end{tabular}

The control sample includes 25 days when no interventions occurred. Control sample observations are matched by time-of-day and day-of-week to the intervention sample. The equality of variances is tested using the Brown-Forsythe (1974) modified Levene test. The null hypothesis is that the sample variances at 5 -min intervals are homoskedastic over the $[-120,+120]$ interval. Critical values are distributed as $F(38,2691)=1.4094(5 \%)$ denoted with * and $1.6202(1 \%)$ denoted with **. The Fed intervention sample includes 70 Reuters reports. The three banks are listed by Euromoney magazine as the most popular among corporate customers in the New York market.

also presents $F$-statistics for equality of variance in the $2 \mathrm{~h}$ surrounding Fed interventions using quotes from individual banks. The banks selected were those listed by Euromoney magazine as the most popular among corporate customers in the New York market. ${ }^{38}$ With the exception of Chemical Bank in the USD-JPY market, the statistics generally do not support the hypothesis that it is individual banks that systematically influence return variance surrounding intervention events. It is said that the Fed generally attempts to use a wide and variable selection of banks for their intervention transactions in order not to give any one bank unfair advantage. The results suggest that these attempts have been quite successful. $^{39}$

\footnotetext{
${ }^{38}$ Euromoney magazine publishes its survey on the foreign exchange market annually. The banks selected appeared regularly (from 1989 to 1995) in the list of the five most popular banks in the NY market.

${ }^{39}$ Alternatively it may be that the indicative quote data are too noisy to pick up individual bank effects. During heavy information periods such as the period surrounding an intervention event it may be that banks are less conscientious about updating quotes.
} 


\section{Conclusions}

The tests in this paper explore whether aspects of market microstructure influence the effectiveness of central bank intervention. In particular, this study examines the importance of the "state of the foreign exchange market" at the moment that central bank intervention operations (and macro announcements) are made public to traders. The empirical evidence indicates that Fed intervention operations significantly influenced both USD-DEM and USD-JPY intra-day returns and volatility. The evidence also suggests that some traders know at least 1 $\mathrm{h}$ prior to the Reuters' report that a central bank is intervening, and the effects of interventions generally persist, at least to the end of the day. There is evidence of mean reversion in returns subsequent to Fed interventions particularly in the USD-DEM market, suggesting some initial over-reaction by the market. Fed interventions that occurred when the US and European markets are open (a proxy for relatively heavy trading volume periods), and in the aftermath of macro announcements had relatively larger effects than those that occurred at other times in the day. Coordinated interventions were also found to have large effects on exchange rates. There is little evidence in the FXFX data that specific large banks in the USD-DEM and USD-JPY markets systematically act as price leaders in reaction to news of Fed intervention.

Overall, the tests in the paper support the hypothesis that central bank interventions influence intra-daily foreign exchange returns and volatility. The results also support the hypothesis that the efficacy of central bank intervention depends on the characteristics of the foreign exchange market at the time the operations become known to traders. The evidence suggests that policy makers that hope to have the largest intra-daily influence on exchange rate returns using intervention operations should time interventions to take place when trading volume is high (when both London and New York are trading) in the aftermath of the release of other macroeconomic news, and when other central banks are also in the market (intervening in the same direction).

\section{Acknowledgements}

I thank Andy Rose (the editor), the referees, seminar participants at the NBER, University of Michigan, and Georgetown University and, in particular, Jay Levin, Richard Lyons, Chris Neely, Matthew Shapiro, Larry Summers, Carol Osler and Shang-Jin Wei for useful comments and suggestions. Tatiana Nenova provided outstanding research assistance. I am grateful to Olsen and Associates for providing the intradaily exchange rates and Reuter's news tape analyzed in the paper. 


\section{References}

Admati, A., 1991. The informational role of prices: A review essay. Journal of Monetary Economics 28, 347-361.

Beattie, N., Fillion, J., 1999. An Intraday Analysis of the Effectiveness of Foreign Exchange Intervention. Bank of Canada Working Paper 99-94.

Brown, M.B., Forsythe, A.B., 1974. Robust tests for the equality of variance. Journal of the American Statistical Association 69, 364-367.

Chaboud, A., LeBaron, B., 2001. Foreign exchange market trading volume and federal reserve intervention. Journal of Futures Markets 21, 851-860.

Chang, Y., Taylor, S., 1998. Intraday effects of foreign exchange intervention by the Bank of Japan. Journal of International Money and Finance 18, 191-210.

Dacorogna, M.M., Muller, U.A., Nagler, R.J., Olsen, R.B., Pictet, O.V., 1993. A geographical model for the daily and weekly seasonal volatility in the FX market. Journal of International Money and Finance 12, 413-438.

Dominguez, K., 1992. The informational role of official foreign exchange intervention operations: the signalling hypothesis. In: Dominguez, K. (Ed.), Exchange Rate Efficiency and the Behavior of International Asset Markets. Garland Publishing Company, NY, pp. 41-80, Chapter 2.

Dominguez, K., 1998. Central Bank intervention and exchange rate volatility. Journal of International Money and Finance 18, 161-190.

Dominguez, K., 1999. The Market Microstructure of Central Bank Intervention. NBER working paper 7337.

Dominguez, K., Frankel, F., 1993a. Does foreign exchange intervention matter? The Portfolio effect. American Economic Review 83, 1356-1369.

Dominguez, K., Frankel, F., 1993b. Does Foreign Exchange Intervention Work? Institute for International Economics, Washington, D.C.

Evans, M., 1998. The Microstructure of Foreign Exchange Dynamics. Georgetown University.

Evans, M., 1999. What are the Origins of Foreign Exchange Movements. Georgetown University.

Evans, M., Lyons, R., 2001. Portfolio Balance, Price Impact and Secret Intervention. National Bureau of Economic Research Working Paper 8356.

Federal Reserve Bank of New York, 1992. Administration of Relationships with Foreign Exchange Trading Counter-parties, February 28.

Fischer, A.M., Zurlinden, M., 1999. Exchange rate effects of central bank interventions: An analysis of transaction prices. Economic Journal 109, 662-676.

Frankel, J., Rose, A., 1995. Empirical research on nominal exchange rates. In: Grossman, G., Rogoff, K. (Eds.). Handbook of International Economics, Vol. 3. Elsevier Science, Amsterdam, pp. 16891729.

Goodhart, C., Hesse, T., 1993. Central Bank forex intervention assessed in continuous time. Journal of International Money and Finance 12, 368-389.

Goodhart, C., Ito, T., Payne, R., 1996. One day in June 1993: A study of the working of the Reuters 2000-2 Electronic foreign exchange trading system. In: Frankel, J., Galli, G., Giovannini, A. (Eds.), The Microstructure of Foreign Exchange Markets. The University of Chicago Press for NBER, pp. $107-179$.

Guillaume, D., Dacorogna, M., Dave, R., Muller, U., Olsen, R., Pictet, O., 1997. From the bird's eye to the microscope: A survey of new stylized facts on the intra-daily foreign exchange markets. Finance and Stochastics 1 (2), 95-129.

Kendall, M.G., Stuart, A., 1958. Advanced Theory of Statistics. Griffin and Company, London.

LeBaron, B., 1999. Technical trading rule profitability and foreign exchange intervention. Journal of International Economics 49 (1), 125-143.

Lyons, R., 1995. Tests of microstructural hypotheses in the foreign exchange market. Journal of Financial Economics 39, 321-351. 
Lyons, R., 1996. Foreign exchange volume: Sound and fury signifying nothing. In: Frankel, J., Galli, G., Giovannini, A. (Eds.), The Microstructure of Foreign Exchange Markets. The University of Chicago Press for NBER, pp. 183-201.

Lyons, R., 2001. The Microstructure Approach to Exchange Rates. MIT Press.

Meese, R., Rogoff, K., 1983. Empirical exchange rate models of the seventies: Do they fit out of sample? Journal of International Economics 14 (1-2), 3-24.

Montgomery, J., Popper, H., 2001. Information sharing and Central Bank intervention in the foreign exchange market. Journal of International Economics 55 (2), 295-316.

Mussa, M., 1980. The Role of Official Intervention. Group of Thirty, New York, NY.

Naranjo, A., Nimalendran, M., 2000. Government intervention and adverse selection costs in foreign exchange markets. Review of Financial Studies 13, 453-477.

Neely, C., 2000. The practice of Central Bank intervention: Looking under the hood. Central Banking XI (2), 24-37.

Neely, C., 2002. The temporal pattern of trading rule returns and Central Bank intervention: Intervention does not generate technical trading rule profits. Journal of International Economics 58, 211-232.

O'Hara, M., 1995. Market Microstructure Theory. Blackwell Business.

Pasquariello, P., 2001. Central Bank Intervention and the Intraday Process of Price Formation in the Currency Markets, Stern School of Business, NYU.

Payne, R., Vitale, P., 2000. A Transaction Level Study of the Effects of Central Bank Intervention on Exchange Rates. London School of Economics.

Peiers, B., 1997. Informed traders, intervention and price leadership: A deeper view of the microstructure of the foreign exchange market. Journal of Finance 52 (4), 1589-1614. 